\title{
The Indian Ocean as a Diasporic Space: A CONCEPTUAL InTRODUCTION
}

\section{Iain Walker}

Max Planck Institute for Social Anthropology

\section{Martin Slama}

Institute for Social Anthropology at the Austrian Academy of Sciences

\begin{abstract}
Over the past two decades there has been a growing interest in Indian Ocean networks within diaspora studies, and within migration studies more generally. In this introduction we develop the idea of the Indian Ocean as a space within which diasporas come into being, endure, and sustain relationships. Taking this Indian Ocean perspective, we suggest that the concept of the diaspora as currently employed in scholarship could be strengthened and we outline some suggestions for a reframing of the concept. Through an emphasis on its enduring character, as a community, and through a decentring of the homeland, we propose to understand a diaspora as a community that is diffuse but coherent, both spatially and temporally, and that has agency, facilitating the activities of its members. This provides a framework for the variety of approaches to the concept in the articles in the collection that follows.
\end{abstract}

The networks linking the shores of the Indian Ocean have long facilitated a constant if sometimes irregular movement of peoples, leading to the establishment of communities both along the ocean's littoral and further inland. Some of these communities have great temporal depth: the Hadramis, for example, who have been present in eastern Africa for centuries, if not millennia; the Gujaratis, who claim to have been responsible for the Islamisation of parts of Southeast Asia; or different groups of Chinese, who in centuries past appear to have settled not only in Southeast Asia but in places as far afield as the Persian Gulf and eastern Africa. In the eighteenth, nineteenth and early twentieth centuries, with the consolidation of the European colonial empires around the Indian 
Ocean, there were renewed movements. Some were forced, or as good as, others were prompted by greater economic opportunities facilitated by easier (if sometimes more expensive) travel. Some of the people moving drew upon pre-existing relationships again, Hadramis or Gujaratis - while others established new communities - Tamils or Chinese in the Mascarenes, for example. Many of these communities continued, and continue, to maintain relationships across the ocean, both with each other and with the homeland, and these relationships are often instrumental in framing contemporary social and cultural practices, constituting individual and group identities, and shaping social, economic and political strategies, thereby providing cohesion within and between these different communities and influencing relationships with others in the host society. They are, of course, diasporas.

For many, the notion of the diaspora invokes classic examples such as Jews, Armenians or Africans, groups of people with their places of origin in the Middle East, the Caucasus and western Africa and dispersed - often with great violence - to locations mainly in Europe and the Americas. The Indian Ocean, by contrast, has historically (and perhaps ironically) received less recognition as a space characterised by diasporic communities and networks - only the African diaspora in the Indian Ocean, often borrowing conceptually, and not always convincingly, from the Atlantic model, attracted much attention. ${ }^{1}$ However, over the past two decades or so, scholarship on African diasporic communities in the Indian Ocean has become more nuanced, ${ }^{2}$ and there has been work on other groups, Hadramis in particular, ${ }^{3}$ but South Asians, including Gujaratis and

\footnotetext{
${ }^{1}$ For example: Edward A. Alpers, "The African diaspora in the northwestern Indian Ocean: Reconsideration of an old problem, new directions for research," Comparative Studies of South Asia, Africa and the Middle East, 17, 2 (1997), 62-81; William Gervase Clarence-Smith, The Economics of the Indian Ocean Slave Trade in the Nineteenth Century (London: Frank Cass, 1989).

${ }^{2}$ See, for example: Hubert Gerbeau, "L'océan Indien n'est pas l'Atlantique. La traite illégale à Bourbon au XIXe siècle," Outre-mers, 89, 336-337 (2002), 79-108; Shihan de Silva Jayasuriya and Richard Pankhurst (eds.), The African Diaspora in the Indian Ocean (Trenton, NJ: Africa World Press, 2003); Kai Kresse and Edward Simpson, "Between Africa and India: Thinking comparatively across the western Indian Ocean,” Berlin: ZMO, ZMO Working Papers 5 (2011); Pier M. Larson, Ocean of Letters: Language and creolization in an Indian Ocean diaspora (New York: Cambridge University Press, 2009); Behnaz Mirzai, A History of Slavery and Emancipation in Iran, 1800-1929 (Austin: University of Texas Press, 2017); Abdul Sheriff, Dhow Cultures of the Indian Ocean: Cosmopolitanism, commerce and Islam (New York: Columbia University Press, 2010); Ineke Van Kessel, "Belanda Hitam: The Indo-African communities of Java," African and Asian Studies, 6, 3 (2007), 243-79; Thomas Vernet, "East African travelers and traders in the Indian Ocean: Swahili ships, Swahili mobilities ca. 1500-1800," in Trade, Circulation, and Flow in the Indian Ocean World, ed. Michael Pearson, (Basingstoke: Palgrave Macmillan, 2015), 167-202.

${ }^{3}$ Ulrike Freitag, Indian Ocean Migrants and State Formation in Hadhramaut: Reforming the homeland (Leiden: Brill, 2003); Engseng Ho, The Graves of Tarim: Genealogy and mobility across the Indian Ocean (Berkeley: University of California Press, 2006); Anne K. Bang, Islamic Sufi Networks in the Western Indian Ocean (c. 1880-1940): Ripples of Reform (Leiden: Brill, 2014). Sumit K. Mandal, Becoming Arab: Creole histories and modern identity in the Malay world (Cambridge: Cambridge University Press, 2018); Christian Lekon, Time, Space and Globalization: Hadhramaut and the
} 
Tamils, ${ }^{4}$ and Chinese, too. ${ }^{5}$

From our perspective, this growing interest in Indian Ocean diasporas is welcome: the Indian Ocean is very much a diasporic space, and it has long been so. People have moved through the region for a multitude of reasons, maintaining (unlike the Atlantic African diaspora, for example) networks across the ocean and beyond, through which people moved for economic, religious, educational, political and family reasons. These networks have long been the focus of scholarship, and it is hard to imagine histories of the ocean that do not have these sorts of connections and movements at their core, even if they haven't explicitly invoked the notion of diaspora. From works by Hourani, Toussaint and Chaudhuri, to those by McPherson, Pearson and Das Gupta, by way of the novels of Amitav Ghosh, the Indian Ocean has long been a space defined by its networks. ${ }^{6}$ Indeed, one of the oldest books known to us - the Periplus of the Erythraean Sea - is about Indian Ocean networks. $^{7}$

The notion of diaspora is in such widespread use in contemporary scholarship that, by way of a conceptual recalibration, it is useful to briefly revisit the history of the term before reconsidering the concept in the context of the Indian Ocean. ${ }^{8}$ The word diaspora is derived from the Greek verb $\delta 1 \alpha \sigma \pi \varepsilon i ́ p \varepsilon \imath v$, to scatter, and was used in the classical period

Indian Ocean rim 1863-1967 (Gleichen: Muster-Schmidt, 2014); Leif Manger, The Hadrami Diaspora: Communitybuilding on the Indian Ocean rim (New York: Berghahn, 2010).

${ }^{4}$ Edward A. Alpers and Chhaya Goswami (eds.), Transregional Trade and Traders: Situating Gujarat in the Indian Ocean from early times to 1900 (New Delhi: Oxford University Press, 2019); Sunil S. Amrith, Crossing the Bay of Bengal: The Furies of nature and the fortunes of migrants (Harvard: Harvard University Press, 2015); Fred Clothey, Ritualizing on the Boundaries: Continuity and innovation in the Tamil diaspora (Columbia: University of South Carolina Press, 2006); Pascale Herzig, South Asians in Kenya: Gender, generation and changing identities in diaspora (Münster: LIT Verlag, 2006); Pedro Machado, Ocean of Trade: South Asian merchants, Africa and the Indian Ocean, c. 1750-1850 (Cambridge: Cambridge University Press, 2014); Lotika Varadarajan (ed.), Gujarat and the Sea (Vadodara: Darshak Itihas Nidhi, 2011). ${ }^{5}$ Abanti Bhattacharya, "The Chinese diaspora in southeast Asia: Chinese nationalism reinforced," Diaspora Studies, 2, 2 (2009), 119-42; Shelly Chan, "The Case for diaspora: A temporal approach to the Chinese experience," Journal of Asian Studies, 74, 1 (2015), 107-28; Philip A. Kuhn, Chinese Among Others: Emigration in modern times (Singapore: NUS Press, 2008); Anshan Li, A History of Overseas Chinese in Africa to 1911 (New York: Diasporic Africa Press, 2012); Adam McKeown, "Conceptualizing Chinese diasporas, 1842 to 1949," The Journal of Asian Studies, 58, 2 (1999), 306-37; Ian Rae and Morgen Witzel (eds.), The Overseas Chinese of South East Asia: History, culture, business (Gordonsville: Palgrave Macmillan, 2008).

${ }^{6}$ George Hourani, Arab Seafaring in the Indian Ocean in ancient and early medieval times (Princeton: Princeton University Press, 1951); Auguste Toussaint, History of the Indian Ocean (London: Routledge and Kegan Paul, 1966); K. N. Chaudhuri, Trade and Civilisation in the Indian Ocean: An economic history from the rise of Islam to 1750 (Cambridge: Cambridge University Press, 1985); Kenneth McPherson, The Indian Ocean: A history of people and the sea (Delhi: Oxford University Press, 1993); Michael Naylor Pearson, The Indian Ocean (London: Routledge, 2003); Ashin Das Gupta, The World of the Indian Ocean Merchant: 1500-1800: Collected essays of Ashin Das Gupta (New Delhi: Oxford University Press, 2001). Ghosh's novels include: Amitav Ghosh, In an Antique Land (London: Granta, 1998).

${ }^{7}$ Lionel Casson, The Periplus Maris Erythraei. Text with introduction, translation, and commentary (Princeton: Princeton University Press, 1989).

${ }^{8}$ For a comprehensive history of the word, see: Stéphane Dufoix, The Dispersion: A history of the word diaspora (Leiden: Brill, 2016). 
to refer to a dispersal of human beings. Only later was the noun diaspora invoked to describe the state of dispersion. It appeared for the first time in the Greek translation of the Septuagint, where it refers to the curse that God placed upon the unlawful Israelites, compelling them to leave their homeland and live in "diaspora." However, following this use of diaspora, as an unhappy state of being that can only be overcome by a return to the homeland, in the New Testament other uses of the term began to appear. Here the word is used to refer not only to Jews who did not live in their homeland, but also to Greeks who, living outside Greece, did not necessarily want to return to (even though remaining in contact with) their homeland; and to Christians who formed a dispersed community through their adherence to a minority religion, but who probably never left their homelands and, equally important, probably never shared a common homeland at all. ${ }^{9}$ What we can learn from this brief excursion into the history of diaspora as a concept is that, from quite early on, the term diaspora denoted different forms of dispersion, real or symbolic, and different forms of relationship with a homeland, all while implying connections and networks between the different people and places that constituted it. In what follows, both insights, the plurality of social formations of diaspora and their networked character, are important, as is the concept of the Indian Ocean not simply as a geographic area, nor simply as a cultural and economic space, but as an instrumental space, as a medium of mobility in and through which diasporas come into being, grow, survive and reproduce themselves, and through which they exercise a certain agency: this is the Indian Ocean as a diasporic space.

The articles in this special issue, and the one on transnational connections and identities in the Indian Ocean that will follow, are the outcome of a conference held in Halle, Germany, in September 2019 with the theme "Us and them: Diasporas for others in the Indian Ocean." "The concept of the "diaspora for others" was first proposed by one of us in the context of his work on the Hadrami diaspora in the western Indian Ocean, largely in response to the growing ubiquity, and accompanying risk of theoretical voiding, of the concept of diaspora itself. ${ }^{11}$ Although a growing number of scholars have, over the

\footnotetext{
${ }^{9}$ Ibid.; Martin Slama and Johann Heiss, "Comparing Arab diasporas: Post-9/11 and historical perspectives on Hadhrami and Syro-Lebanese communities in Southeast Asia and the Americas," Comparative Studies of South Asia, Africa and the Middle East, 31, 2 (2011), 231-250.

${ }^{10}$ This conference was held at the Centre for Interdisciplinary Regional Studies (ZIRS), Martin Luther University HalleWittenberg. It was funded by Fritz Thyssen Stiftung für Wissenschaftsförderung, the Deutsche Forschungsgemeinschaft, and ZIRS. The organisers wish to acknowledge their generous support.

${ }^{11}$ Iain Walker, "A 'diaspora-for-others': Hadramis in the world," in Diasporas Reimagined: Spaces, practices and belonging, eds. Nando Sigona, Alan Gamlen, Giulia Libertore, and Hélène Neveu Kringelbach (Oxford: Oxford Diasporas Programme, 2015), 83-6. This is developed in more detail in Walker's article in this special issue: Iain Walker, "The
} 
years, raised these concerns, ${ }^{12}$ scholarship generally does not seem to have paid much heed, continuing to use the word diaspora to stand, somewhat indiscriminately, for "migrant community." One reason for this would appear to be the fact that the concept of the diaspora is a useful one, with a deep history and much analytic potential. Despite thoughtful attempts to find alternative conceptual frameworks, these often flounder, and the concept of the diaspora reasserts itself. Thus, for example, in an insightful article that contests the monolithic conceptualisation of a (single) Chinese diaspora, Adam McKeown writes eloquently of nodes and flows, multiplicity and hybridity, but then, pace his own rhetoric, reverts to discussing the Chinese diaspora. ${ }^{13}$

Invoking a "diaspora for others," the framing concept for the conference, is therefore an attempt to salvage some of the original characteristics of the term, referred to above, particularly that of a group of people who maintain a sense of cohesion and of collective identity that is of both symbolic and practical significance, across time and space. The emphasis is therefore on the ties that bind: a "diaspora for others" is a spatially dispersed community, not simply a group of migrants who come from one place and live together in another; and it is one that does indeed function as a community, even if that community can be formed in different ways and might suffer from internal frictions - as all communities do. ${ }^{14}$

A second rationale for this theoretical reorientation lies in a desire to move away from spatial definitions of identity and the concomitant premise that spatially dispersed groups have a place of origin, and thereby attachments and orientations, elsewhere. While this may be literally true, in that individuals or their ancestors did indeed come from elsewhere, many diasporans, just like the above-mentioned ancient Greeks outside Greece, have not only never visited the homeland, but many never intend to visit it: diasporans belong where they are, and not somewhere else. By the same token, many diasporans who do choose to visit the homeland find themselves in unfamiliar surroundings, both physically and socially: culturally incompetent and surrounded by people they neither know nor understand, they are often quite uncomfortable, they do not belong. This is not to deny the existence of a homeland, and the role that homelands may

Hadrami diaspora: A “diaspora for others" in the Indian Ocean," Journal of Indian Ocean World Studies, 4, 2 (2021), 188210.

${ }^{12}$ Rogers Brubaker, "The 'diaspora' diaspora," Ethnic and Racial Studies, 28, 1 (2005), 1-19; Thomas Faist, "Diaspora and transnationalism: What kind of dance partners?" in Diaspora and Transnationalism: Concepts, theories and methods, eds.

Rainer Bauböck and Thomas Faist (Amsterdam: Amsterdam University Press, 2010), 9-34.

${ }^{13}$ McKeown, "Conceptualizing Chinese diasporas," 310.

${ }^{14}$ For the latter instance, see: Martin Slama, "Marriage as crisis: Revisiting a major dispute among Hadhramis in Indonesia," Cambridge Anthropology, 32, 2 (2014), 65-80. 
play symbolically, and even practically, in consolidating diasporic identity, nor even the fact that many diasporans are not held to belong in the places where they live, frequently facing discrimination; but a denial of belonging by others does not necessarily mean that the victims of such discrimination do not belong. ${ }^{15}$ This is almost banal: Zanzibaris of Omani origin, for example, being told to go home when they are already at home. ${ }^{16}$

A third consideration is one of diasporic identity itself. If not all of those whose origins lie elsewhere are diasporic, then which of them are? How do we decide whether a dispersed group of people whose origins lie in the same specific place constitute a diaspora? Diaspora exists in an intermediate position between groups that have not (yet) developed a sense of belonging there where they are, and those that belong in full, or as fully as possible. The latter are those who have fully assimilated and who are no longer identifiable by any sort of affinities, attachments or social or cultural points of reference other than in the place in which they live. Descendants of the Angles living in England are a good example: it is doubtful whether very many English people feel any sense of diasporic solidarity with their erstwhile compatriots in their northern German homeland, or with descendants of these peoples elsewhere, or yearn for the marshes of SchleswigHolstein. Indeed, the very idea probably raises a smile. There often (not always: Jews are the classic example; but religion is often a more durable trait) comes a point at which diasporic identity disappears, when the group is no longer distinguishable from others amongst whom they live: assimilation is complete, the differences between groups are no more significant, less, even, than those within groups.

The former group is somewhat harder to differentiate. They will generally be recent or temporary migrants, clearly identifiable by their practices and who will probably themselves admit that they do not (yet) belong. They may well intend to remain where they are, however, in which case they can be characterised as "pre-diasporic," particularly if they have joined members of an ethnic group already living in diaspora; or they may not, intending to eventually return home as soon as conditions permit. We might cite Syrian refugees in early $21^{\text {st }}$-century Europe as an example. Unlike, perhaps, Armenians or Jews in the past, Syrians are not excluded from Syria merely by virtue of their being Syrian, and a return will presumably be a possibility once the war is over; yet at the same

\footnotetext{
${ }^{15}$ Martin Slama, “An old diaspora and its new connections. Indonesian Hadhramis and the Hadhramaut," Antropologi Indonesia, 78 (2005), 107-13; Ismail Fajrie Alatas, "The poetics of pilgrimage: Assembling contemporary Indonesian pilgrimage to Hadramawt," Comparative Studies in Society and History, 58, 3 (2016), 607-35.

${ }^{16}$ Mandana Limbert, "Personal memories, revolutionary states and Indian Ocean migrations," The MIT Electronic Journal of Middle East Studies, 5 (2005), 21-33.
} 
time, there is a large Syrian (or perhaps more accurately Syrian-Lebanese) diaspora that they might join. ${ }^{17}$

Nevertheless, we suggest that most first-generation migrants who are not already part of a diaspora do not generally qualify as diasporic under the definition being proposed here. Many live in a strange land and do not yet master the local language, many still harbour a desire to return home, and many will do so once conditions permit. Diasporans, on the other hand, are at home in the places where they live. They speak the language, practice the culture, are socially integrated. This is not to say that first generation migrants will not become diasporic, as they are often already in the process of becoming. This, we suppose, is the crucial distinction, and here we diverge from Robin Cohen, who included a lack of integration as a criterion for definition as a diaspora: "a troubled relationship with host societies, suggesting a lack of acceptance." 18 Rather, we hold that it is equally an element of any definition of diaspora that a diasporic community has become part of the host society, even if partially or incompletely, and despite, possibly, the reluctance of (or parts of) the host society to acknowledge that. We are well aware that the line of distinction between groups of migrants and exiles on the one hand and diasporas on the other can be thin, as the process of becoming diasporic can start from the first day of one's arrival. Yet what we want to stress is that members of diasporas are not people out of place, outside their homeland, but that they join others in constituting the place where they are, sometimes decisively influencing its history. The latter is particularly true for the Indian Ocean diasporas discussed in these two special issues: Hadrami, Omani, Gujarati and Chinese diasporic communities have not only become part of but are deeply embedded in the social histories of various sites across the Indian Ocean.

One reason for considering the degree to which diasporic groups are accepted by the host societies is that it decentres the homeland. While the homeland nevertheless retains a certain symbolic priority, in a practical sense it is simply another node in the network of relationships that constitute diasporas for others. In fact, relationships with the homeland are often ambiguous, and homelands are often less attractive places in a

\footnotetext{
${ }^{17}$ Although "joining" diasporas is not always straightforward. Lebanese Australians whose presence dates from the early 20th century, were not always well-disposed towards Lebanese arriving in the country towards the end of the century. See: Michael Humphrey, "The Lebanese war and Lebanese immigrant cultures: A comparative study of Lebanese in Australia and Uruguay," Ethnic \& Racial Studies, 9, 4 (1986), 445-60; Nelia Hyndman-Rizik, "'Shrinking worlds': Cronulla, antiLebanese racism and return visits in the Sydney Hadchiti Lebanese community," Anthropological Forum, 18, 1 (2008), 3755; Paul Tabar, "Politics among Arab migrants in Australia," in Politics, Culture and the Lebanese Diaspora, eds. Paul Tabar and Jennifer Skulte-Ouaiss (Newcastle: Cambridge Scholars Publishing, 2010), 294-334.

${ }^{18}$ Robin Cohen, Global Diasporas: An Introduction (Abingdon: Routledge, 2008), 17.
} 
diasporic space. ${ }^{19}$ This is certainly true for, for example, Comorian Hadramis, for whom places in East Africa, Europe and the Gulf are far more desirable destinations for further movement than Hadramawt itself. Indeed, do diasporas even need a homeland? Possibly not: James Clifford has questioned the putative attractions of the homeland, and the Roma, for example, seem to survive without one. ${ }^{20}$ And yet, almost regardless of the role of the homeland, there is a sense of diasporic identity that is based on shared social and cultural practices and shared narratives of origin, and this sense of identity differentiates members of the diaspora from other people around them. This reminds us of early Christians, who were seen as a diaspora on the basis of their shared religion. Decentring the homeland allows us to view a diaspora as a spatially dispersed group whose spaces include the homeland, but in which the homeland is simply another space inter pares. The implications are that a diaspora may therefore be conceptualised as a spatially dispersed group that, while making symbolic appeals to a homeland, or being constrained to do so, is not physically bound by it. It is not without significance that for those in the homeland, members of the diaspora do not always seem to belong. People in Hadramawt use epithets such as "Saudis", "Zinjbaris" and "Indonesians" to refer to people who in these other places may well be identified as Hadramis but who, for them, are foreigners.

Following this line of thought, we may also ask how and why some groups are able to constitute and maintain a diasporic identity. Why are Hadramis in Zanzibar characterised as diasporic, but not Makua? Here we encounter questions of power and agency, the ability of members of diasporas not only to maintain their cultural identities, for example under colonial domination - British racial classification was fundamental to the colonial enterprise and those whose group identities allowed them to claim privileges did their utmost to maintain them - but also to sustain the networks that bind the diaspora together. ${ }^{21}$ To pursue the example of the Makua, Makua were enslaved and deported not only to various places around the Indian Ocean, but also the Americas; and yet (and despite various peoples bearing the epithet "Makua") there is (or there seems to be) no Makua diaspora: not only were the Makua subsumed within the category of "native" in

\footnotetext{
${ }^{19}$ Slama, "An old diaspora," 107-13; Iain Walker, "Comorians and Hadramis in the western Indian Ocean: Diasporic practices in a comparative context," Social Dynamics, 38, 3 (2012), 435-53.

${ }^{20}$ James Clifford, "Diasporas," Cultural Anthropology, 9, 3 (1994), 302-38. For the Roma example, see: Carol Silverman, Romani Routes: Cultural politics and Balkan music in diaspora (Oxford: Oxford University Press, 2012).

${ }^{21}$ Iain Walker, "L'identité comorienne dans le protectorat britannique de Zanzibar," Ya Mkobe, 16-17 (2012), 75-84; Iain Walker, "Identity and citizenship among the Comorians of Zanzibar, 1886-1963," in The Indian Ocean: Oceanic connections \& the creation of new societies, eds. Abdul Sheriff and Engseng Ho (London: Hurst \& Co, 2014), 239-66.
} 
the places to which they were sent, they had neither the means nor, presumably, any particular motivation to develop a diasporic identity.

A further question is how diasporas are defined and named (the two not being unrelated): what are the parameters for constituting or belonging to a given diaspora? Or, to turn the question around, what sorts of groups are liable to constitute diasporas? Are people whose ancestors left Hadramawt, where they belonged to different groups, all members of a Hadrami diaspora? Or are there a number of Hadrami diasporas, differentiated by space, time, status, kin? Is there an Alawiyya diaspora, as both Wilson Jacob and Fatimah Husein suggest? ${ }^{22}$ Is there a mashaykh diaspora and a masakin diaspora? A Kathiri diaspora and a Qu'aiti diaspora? ${ }^{23}$ A diaspora constituted by those whose ancestors left Hadramawt in the 18th century and another for those who left in the 19th? And are Hadramis themselves just part of a Yemeni diaspora, an Arab diaspora or even an Islamic diaspora? The difficulties inherent in answering such questions are implicitly answered (or perhaps more correctly, side-stepped) by many scholars in contemporary characterisations of diasporic groups as being identified with independent states: the Tanzanian diaspora, the Congolese diaspora, the Mexican diaspora. It is a simple enough matter to identify a Tanzanian: show me your passport. These are essentialised groups, well-defined by definition, and thus far less slippery than a Hadrami who may on occasion be a sayyid, on others an Arab. We need to move away from essentialised groups and essentialised spaces: shifting the definition of diaspora away from the state liberates diaspora from the constraints of the state and from nationalism, whether methodological, theoretical or practical. Caution is still called for, however. For practical purposes we need to name the objects of our endeavours, which can again lead to back essentialisation: there is a fine line to tread between analysing the Hadrami diaspora and conceptualising "Hadrami" as a bounded group, regardless of whether or not the group is a "nation" or emerges from a state.

A move away from nationalist definitions is perhaps easier in the Indian Ocean since, as the list above suggests, many Indian Ocean diasporas are not defined by reference to a state to start with, partly because the diasporas in question pre-date the states of which their homelands are now a part - Gujaratis, Hadramis and Tamils were travelling the

\footnotetext{
${ }^{22}$ Wilson Chacko Jacob, For God or Empire: Sayyid Fadl and the Indian Ocean world (Stanford: Stanford University Press, 2019); Fatimah Husein, "Preserving and transmitting the teachings of the Thariqah 'Alawiyya: Diasporic Ba 'Awali female preachers in contemporary Indonesia," Journal of Indian Ocean World Studies, 4, 2 (2021), 91-113.

${ }^{23}$ Iain Walker, "Citizenship and belonging amongst the Hadramis of Kenya," in Hadhramaut and its Diaspora: Yemeni politics, identity and migration, ed. Noel Brehony (London: I. B. Tauris 2017), 164-86.
} 
Indian Ocean long before Yemen or India became independent states - and partly because some of the homelands, or their inhabitants, are in conflict with the central state, if not physically, then socially or culturally. Despite these observations, we should nevertheless make it clear that while we wish to conceptually liberate diasporas from the clutches of the nation, and of the state, we are not suggesting that the state should be ignored altogether. States have often played - and continue to play - decisive roles in how diasporas are defined and how diasporans were able to develop a sense of belonging. Both colonial and post-colonial states exercised and continue to exercise their power to categorise people and to regulate their movements, and while many diasporas seem to be skilled in negotiating state bureaucracies, these bureaucracies nevertheless present challenging obstacles for many of those who want to travel through their diasporic networks, or to settle in another diasporic site.

Finally, it is worth making an observation that might perhaps appear mundane, selfevident even, but which is often lost in discussions of, and above all, definitions of diaspora: that, as Guccini and Zhang observe, we should be "[paying] attention to what diaspora does rather than what it is," otherwise any attempt at analysis becomes little more than philosophical musings. ${ }^{24}$ Diasporas serve purposes, they have very real effects on people's lives, whether it be allowing a Hadrami in Zanzibar to entertain imaginaries of his home in the wadi, ${ }^{25}$ thus contributing to his construction of a sense of his own identity, or whether it be allowing a Chinese Mauritian to benefit from advantages (be they material or symbolic) conferred upon him or her by the Chinese government. Diasporas are real, not just analytical categories, and they do things.

\section{The Collection}

The conference call sought contributions that would consider the contemporary character of Indian Ocean diasporas, looking at diasporans' relationships with others in the places in which they live, certainly, but also and particularly with other members of the diaspora elsewhere, as well as with people in the homeland. We were particularly interested in the dynamics of trans-diasporic relationships and the implications of such relationships for a whole diasporic identity. ${ }^{26}$ The hope was that the call would elicit responses from scholars

\footnotetext{
${ }^{24}$ Federica Guccini and Mingyuan Zhang, “'Being Chinese' in Mauritius and Madagascar: Comparing Chinese diasporic communities in the western Indian Ocean," Journal of Indian Ocean World Studies, 4, 2 (2021), 105-6.

25 Walker, "Comorians and Hadramis," 435-53.

${ }^{26}$ By trans-diasporic we refer to relationships across different locations within a single diaspora - see: Walker, "The Hadrami diaspora," 194-5.
} 
working amongst diasporas with member communities dispersed in a variety of sites across the Indian Ocean - we were thinking particularly of Gujaratis, Tamils, Chinese and Hadramis - and indeed it did. Only the Tamil diaspora was not represented. ${ }^{27}$ The response was most satisfying and provided us with an excellent collection of papers - there were 20 presentations at the conference, of which five were selected for publication in this, the first of two special issues to emerge from the conference - even if the trans-diasporic character of the concept of diaspora for others was not always fully addressed. There are obvious reasons for this, and they are largely methodological, even logistical, rather than theoretical in character: research across a wide range of diasporic communities requires not only significant time and funding, but a command of several languages and access to a spatially dispersed network of informants (a diaspora, naturally). These constraints, as they often are, are not easy to overcome. However, this most certainly does not detract from the quality of the contributions presented at the conference. The diasporas under consideration were, for the most part, what we would indeed consider to be diasporas for others. Although most participants were anthropologists or historians, music, area studies, literary and religious studies were also represented; their case studies were drawn from various parts of the ocean, from South Africa to Indonesia, and their papers, and the articles included here, collectively addressed the central themes of transnational networks and diasporic identities in a variety of ways.

A fitting place to start might be to ask what sorts of groups constitute diasporas. If the obvious response might be ethnic or religious groups, we might ask how these groups are defined. Do we require groups to exhibit some sort of ethnic cohesion, to share cultural practices or social structures? If so then this would probably (and despite the rhetoric of the Chinese government) exclude the "Chinese" diaspora, whose home population accounts for almost $20 \%$ of humanity, dozens of ethnic groups and probably as many languages; and, indeed, if the Chinese do seem to either claim or display a sense of shared identity, they simultaneously recognise their internal differences. ${ }^{28}$ In "Being 'Chinese' in Mauritius and Madagascar," Federica Guccini and Mingyuan Zhang discuss nineteenth century Chinese migrations to the western Indian Ocean under different European colonial regimes, highlighting precisely the lack of homogeneity among migrants who belonged to different groups with different identities and speaking different languages, in this case, Cantonese and Hakka. They describe how the Chinese communities dispersed in the

\footnotetext{
${ }^{27}$ These are the most obvious dispersed diasporic groups in the ocean but there are certainly others who, if perhaps less ubiquitous (such as Omanis), might also be considered diasporas for others.

${ }^{28}$ See also: McKeown, "Conceptualizing Chinese diasporas," 306-37.
} 
region developed in a close relationship with one another (and thus certainly coming to constitute a diaspora for others), even if there was sometimes tension and rivalry between Cantonese and Hakka. In the second half of the twentieth century these established diasporic communities saw new migrants arrive from China, in the context of that country's renewed political and economic engagement with African states, prompting Guccini and Zhang to emphasise both diversity and transculturality as defining features of contemporary diasporic Chinese in the region. They reveal how, as the Chinese state courts the diaspora, official versions of Chinese-ness that leave no room for the expression of internal differences are often at odds with the hybrid cultural realities of the creole Chinese communities in Mauritius and Madagascar. Given the different historical trajectories of these communities and the current political moment, Guccini and Zhang argue, negotiations will continue between forces that stress Chinese homogeneity and the strengthening of ties with "the homeland" (mainland China), and those who put an emphasis on heterogeneity and belonging in the societies of Mauritius and Madagascar.

If Guccini and Zhang explore the implications of the rediscovery of a diaspora by a homeland state with particular political ends in mind, Shanaaz Mohammed considers counter-hegemonic notions of diaspora as expressed in literature, and particularly in the Mauritius of Khal Torabully. Although the Aapravasi Ghat is ostensibly imbued with significance for Mauritians of South Asian, and specifically Hindu, origin, Torabully consistently and convincingly re-presents the site of indentureship as one that promotes a culture of diversity, invoking the different origins - Chinese and African as well as South Asian - of the various immigrants recruited through the indentured labour system, and thereby challenging the Aapravasi Ghat as a representation of South Asian indentured memory. Revisiting Mauritian society as diasporic, but with a variety of constitutive sources, effectively characterises the Mauritian diaspora as a converging one inscribed within the diasporic space of the Indian Ocean. At the same time, Mohammed points to the limits of Torabully's multiculturalism. While his work challenges a South Asiancentrist perspective on Mauritian diasporic society, this is expressed through a cultural idiom that is very much rooted in the South Asian cultural realm, such as when he relies on the Indian social type of the fakir. Nevertheless, as Mohammed also argues, Torabully's work virtually embodies the Indian Ocean as a diasporic space that is certainly not devoid of internal hierarchies and power asymmetries.

If we can accept that diasporas may be conceptualised as having multiple homelands, what about diasporas with no homeland? Harun Rasiah's "An Imagined Diaspora" takes the Shi'i Muslims of Sri Lanka as its case study, and although there is 
some movement within the community, the members are almost without exception Sri Lankans. This raises the intriguing question of whether migration is an essential part of the definition of a diaspora, and whether the hostland can be the homeland. What if, rather than being the product of an exodus, flight to a foreign land, a diaspora was instead the product of othering by people, fellow citizens, former friends and neighbours, in one's homeland - the transformation, by exclusion or rejection, of the homeland into the hostland. If the homeland is no longer home, then members of such a diaspora (if diaspora it be) are left without a homeland to invoke and to which to imagine a return. Sri Lankan Shia seem to have established themselves as a diaspora without being descended from people from the homeland, being instead constituted, as were early Christians, as a diasporic community through rejection by their home society: home becomes host through a re-classification of the group rather than through movement. If Rasiah permits, perhaps we can rework his citing of Cheran: maybe diaspora, too, is a condition of living rather than (or in addition to) a condition of leaving; or perhaps the leaving was a social leaving and not a physical one. ${ }^{29}$ If a diaspora without homeland is not entirely without precedent, Rasiah's case study raises (more) interesting (and unanswered) questions about the exact nature of a diaspora. Once again, we are back to what a diaspora does, rather than what it is, or how we define it.

If the multi-cultural, multi-ethnic Chinese seem to be too diverse a group to produce a single diaspora, are some groups too small? The Ba 'Alawi, the focus of Fatimah Husein's article ("Preserving and Transmitting the Teachings of Thariqah 'Alawiyyah") are a Hadrami lineage, descendants of the Prophet Muhammad through Ahmad alMuhajir, "the migrant," who settled in Hadramawt in the fourth century of the Hegira but can families (for the $\mathrm{Ba}$ "Alawi are but a very large family) constitute diasporas? Once again, the response lies not in definition but in function: members of the group share and maintain a sense of group identity across time and space, a collective sense of identity based on a shared origin (real or imagined), and are able to draw upon the networks constructed through this shared sense of identity in order to achieve symbolic or practical aims. Specifically, this is achieved through their membership and transmission of the Tariqah 'Alawiyyah that Husein examines from the perspective of Ba 'Alwi female religious authority. Husein shows how a generation of female Hadrami preachers has emerged in Indonesia who engage with this Sufi tradition - historically a predominantly

\footnotetext{
${ }^{29}$ Rudhramoorthy Cheran, Diaspora Circulation and Transnationalism as Agents for Change in the Post Conflict Zones of Sri Lanka (Berlin: Berghof Foundation for Conflict Management, Policy paper 4, 2003).
} 
male brotherhood - and transmit its teachings to an audience that transcends the Ba 'Alawi Hadrami community. Although they teach the tariqah to non-Hadramis, their religious authority is quintessentially diasporic, since they are not only Hadrami by descent, but they also studied in the schools of Hadramawt. Husein argues that through following diasporic trajectories that cross the Indian Ocean, Ba 'Alawi female preachers have acquired new roles and attracted new audiences, strengthening their position in both the $\mathrm{Ba}$ 'Alawi community and the wider society of Indonesian Muslims.

The Hadrami diaspora is also the focus of Iain Walker's article, although he takes us to the other end of the Indian Ocean. He begins, however, by developing in greater detail the theoretical framework we have outlined above, calling for a recentring of the concept of the diaspora in an attempt to salvage what is useful in the term. This is contingent upon the recognition of diaspora as a plurilocal community with instrumental potential. The recognition of the spatially dispersed character of a diasporic community requires that, in any analysis of diasporic formations, particular attention be paid to relationships between members of a diaspora both within specific locations and between locations, including the homeland. This framework underpins Walker's ethnography, which he uses to illustrate how diasporans act strategically in the different localisations of the Hadrami diaspora on the western shores of the Indian Ocean. Diasporic belonging allows people with Hadrami identities to move through a diasporic space, drawing upon their relationships as they make decisions about their life trajectories, calling on and meeting obligations, soliciting and returning favours, seizing opportunities, consolidating network affiliations. Thus people move, from the Comorian island of Ngazidja, through the Swahili towns of Lamu and Zanzibar, to Dar es Salaam, Hadramawt itself, and the emirates of the Persian Gulf: they draw on their diasporic connections, their kin links, their religious networks, but also engage the knowledge derived from their diasporic identities, a result of their belonging to a spatially dispersed community. The trajectories of these diasporans illustrate well how knowledge, if only partial, of the different aspects of Hadrami diasporic practices allow them to move through different social and cultural contexts, to engage strategies, to achieve (or, sometimes, fail to achieve) certain ends. Here we have the instrumental character of diasporic practice: while diasporic belonging may provide a framework for identity, for an affective sense of being in the world, it also provides for very real courses of action that have visible and material outcomes in addition to symbolic ones.

Understanding the Indian Ocean as a diasporic space allows us to pay heed to the plurality of diasporas in the Indian Ocean while simultaneously reflecting on the notion 
of diaspora itself. Emphasising plurality, however, does not mean subscribing to an allencompassing definition of diaspora. As we have suggested in this introductory article, there is a need to reflect upon the different social formations of diasporic communities and about what actually makes them diasporic. In particular, it is clear that in some of our cases, ancestral homelands do not (or no longer) play such decisive roles in how diasporas constitute themselves. Indeed, although they may remain nodes in the networks of dispersed groups, homelands can be sites of ambivalence and uncertainty, even irrelevance, and not always places towards which diasporic desires and aspirations are directed. One implication of this is that it is essential to recognise that every diasporic location is potentially of equal significance, in the Indian Ocean world and beyond: for a diaspora for others, these places are all homes, and diasporic groups are as local as they are transnational, even if their statuses and roles, and the statuses and roles of the diasporic individuals who compose them, vary from place to place.

The Indian Ocean world is a space of connections and networks, of all kinds - local and translocal, regional, national and transnational - that bind a variety of dispersed communities together. These diasporic communities may be characterised not so much as multi-sited but as plurilocal: not as collections of different communities each of which makes claims to a shared identity based on origins in spatially and temporally distant homelands, but rather as a network of spatially dispersed and geographically overlapping communities that exhibit a dynamic cohesion that is rooted in historical configurations, spatial particularities and contemporary practices. ${ }^{30}$ The Indian Ocean world is a realm in which diasporic, plurilocal socialities, embedded within a matrix of internal and external relations, constantly and repeatedly reassert, renew and reconfigure themselves.

\footnotetext{
${ }^{30}$ See also: Ghassan Hage, “A not so multi-sited ethnography of a not so imagined community," Anthropological Theory, 5, 4 (2005), 463-75.
} 